\title{
ANALISIS KAPASITAS JARINGAN DRAINASE DENGAN APLIKASI HEC-RAS DI KELURAHAN KEDOYA UTARA
}

\author{
Mario $^{1}$, Arianti Sutandi ${ }^{2}$, dan Vittorio Kurniawan ${ }^{3}$ \\ ${ }^{1}$ Program Studi Sarjana Teknik Sipil, Universitas Tarumanagara, Jl. Letjen S. Parman No.1 Jakarta \\ mario.325150014@stu.untar.ac.id \\ ${ }^{2}$ Program Studi Sarjana Teknik Sipil, Universitas Tarumanagara, Jl. Letjen S. Parman No.1 Jakarta \\ ariantis@ft.untar.ac.id \\ ${ }^{3}$ Program Studi Sarjana Teknik Sipil, Universitas Tarumanagara, Jl. Letjen S. Parman No.1 Jakarta \\ vkurniawan@ft.untar.ac.id
}

Masuk: 06-07-2020, revisi: 18-08-2020, diterima untuk diterbitkan: 02-11-2020

\begin{abstract}
Kedoya Utara Village is an area which is almost always flooded with a height that can reach $1 \mathrm{~m}$ every year. Therefore, this study was conducted to determine whether the inundation is caused by channel capacity factors. This study will discuss 9 PHB channels found in Kedoya Utara Village. The data used in this study were obtained from the West Jakarta Water Resources Office, BMKG, and field measurements. Based on calculations obtained 4 channels that have a discharge plan that exceeds the channel capacity of 0,0797-5,7168 $\mathrm{m}^{3} / \mathrm{s}$, so the channel dimensions need to be enlarged from 0-2,45 $\mathrm{m}$ for the width of the channel base, 0-2,3 $\mathrm{m}$ for the width of the section over the channel, and 0,25-0,65 $\mathrm{m}$ for the channel height. From the modeling results it is found that the water level for the four channels exceeds the height of the channel causing flooding in the area around the 4 channels. The location of the flood is in accordance with the reality on the ground. In 2016 the four canals were flooded with almost the same rainfall and the deepest inundation point was on Jalan Panjang.
\end{abstract}

Keywords: Channel capacity; HEC-RAS; Kedoya Utara

\begin{abstract}
ABSTRAK
Kelurahan Kedoya Utara merupakan wilayah yang hampir selalu tergenang banjir dengan ketinggian yang bisa mencapai $1 \mathrm{~m}$ setiap tahunnya. Oleh karena itu, penelitian ini dilakukan untuk mengetahui apakakah genangan tersebut disebabkan oleh faktor kapasitas saluran. Penelitian ini akan membahas 9 saluran PHB yang terdapat di Kelurahan Kedoya Utara. Data yang digunakan dalam penelitian ini diperoleh dari Suku Dinas Sumber Daya Air Jakarta Barat, BMKG, dan pengukuran ke lapangan. Berdasarkan perhitungan didapat 4 saluran yang memiliki debit rencana yang melebihi kapasitas saluran sebesar 0,0797-5,7168 $\mathrm{m}^{3} / \mathrm{s}$, sehingga dimensi saluran perlu diperbesar 02,45 m untuk lebar dasar saluran, 0-2,3 m untuk lebar bagian atas saluran, dan 0,25-0,65 m untuk tinggi saluran. Dari hasil permodelan didapat bahwa ketinggian muka air untuk keempat saluran tersebut melebihi tinggi saluran sehingga menyebabkan terjadinya banjir pada daerah di sekitar 4 saluran tersebut. Lokasi banjir tersebut sesuai dengan kenyataan yang ada di lapangan. Pada tahun 2016 keempat saluran tersebut tergenang banjir dengan curah hujan yang hampir sama dan titik genangan terdalam berada di Jalan Panjang.
\end{abstract}

Kata kunci: Kapasitas saluran; HEC-RAS; Kedoya Utara

\section{PENDAHULUAN}

Di Kecamatan Kebon Jeruk, daerah Kedoya Utara merupakan daerah yang padat penduduk. Berdasarkan data, penduduk di Kelurahan Keyoda Utara pada tahun 2018 ada sebanyak 54.582 penduduk (Pemerintah Provinsi DKI Jakarta, 2018). Hampir setiap tahun penduduk tersebut selalu terkena dampak dari tingginya genangan air yang ada pada Kelurahan Kedoya Utara seperti yang terlihat pada Gambar 1. 


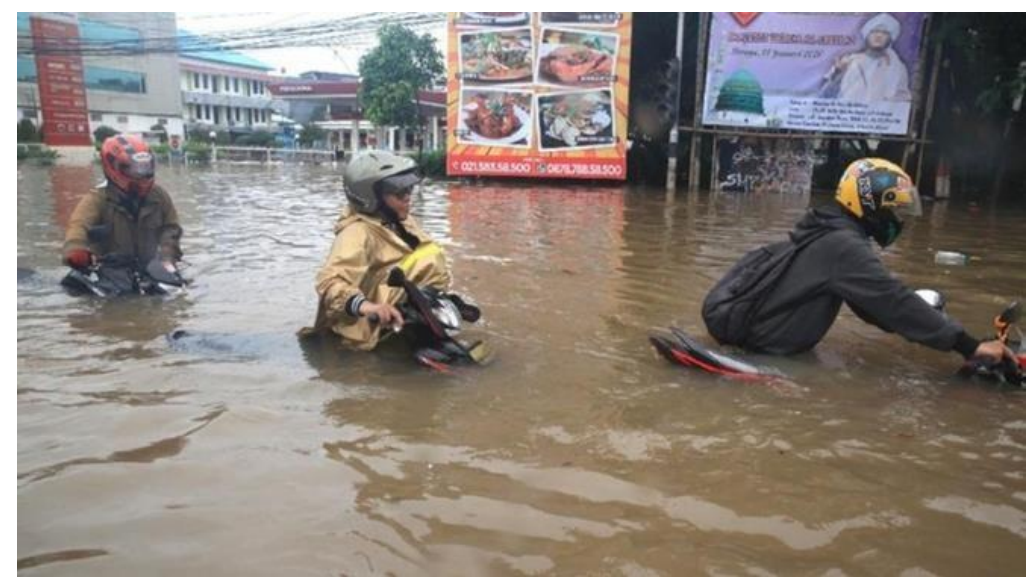

Gambar 1. Banjir di Kelurahan Kedoya Utara (DetikNews, 2016)

Genangan di daerah perkotaan dapat disebabkan oleh berbagai hal. Cara penanggulangan banjir akan berbeda-beda tergantung dari penyebabnya. Oleh karena itu perlu dilakukan penelitian untuk mengetahui apakah genangan tersebut terjadi karena faktor saluran drainase atau faktor lainnya.

Tujuan penelitian ini adalah:

1. Mengetahui penyebab genangan yang terjadi di Kelurahan Kedoya Utara

2. Mengetahui apakah saluran drainase eksisting mampu menampung debit rencana maksimum

\section{Saluran PHB}

Saluran PHB adalah saluran penghubung yang menerima aliran air dari saluran jalan (saluran tersier) dan mengalirkannya menuju saluran sungai (saluran primer). Hal ini dibuktikan dengan Gambar 2 yang menunjukkan arah aliran dari Saluran PHB Green Garden menuju sungai dan Gambar 3 yang menunjukkan bahwa Saluran PHB Taman Ratu menerima limpasan air dari saluran jalan karena memiliki kedalaman saluran yang lebih dalam.

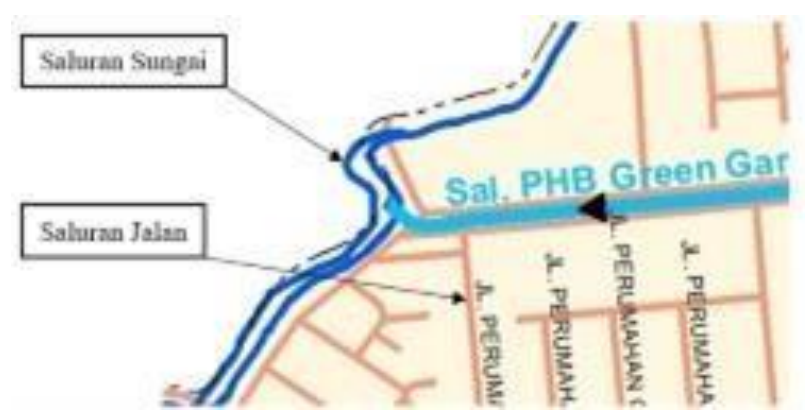

Gambar 2. Peta jaringan drainase kawasan Kedoya Utara (Sumber: Suku Dinas Sumber Daya Air Jakarta Barat, 2020)

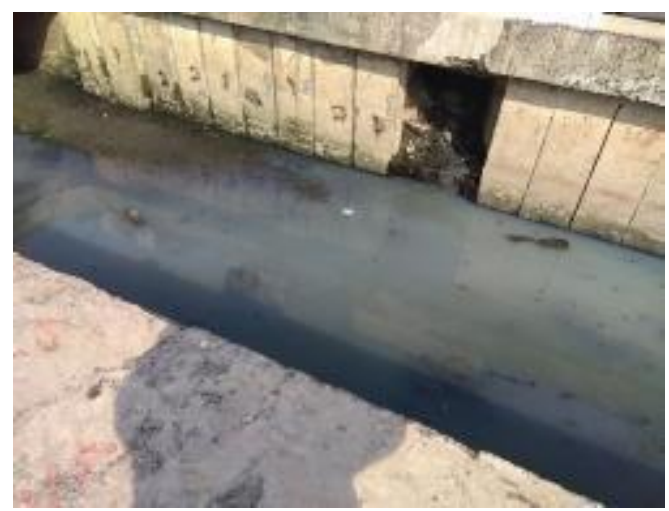

Gambar 3. Buangan saluran jalan ke Saluran PHB Taman Ratu 


\section{Pemilihan fungsi distribusi (dikutip dari SNI 2415:2016)}

Data debit banjir sesaat hasil pengamatan > 20 tahun dibuat histogramnya yang membentuk suatu kurva dan coba untuk didekati dengan salah satu fungsi distribusi seperti distribusi Normal, Log Normal, Gamma, Pearson, Log Pearson, Gumbel dan lain-lain. Fungsi distribusi yang paling dekat dengan data observasi digunakan untuk menghitung besarnya banjir/ hujan rencana.

Pengujian terhadap hubungan antara fungsi distribusi data obserasi dan fungsi distribusi terpilih dapat menggunakan tes Chi-Square atau Kolmogorov - Smirnov.

\section{Periode ulang}

Dalam menentukan periode ulang ada 2 hal yang perlu diperhatikan, yaitu tipologi kota dan luas daerah pengaliran saluran seperti yang tertera pada Tabel 1 (Kementerian Pekerjaan Umum, 2014).

Tabel 1. Tabel penentuan periode ulang

\begin{tabular}{|c|c|c|c|c|c|}
\hline \multirow{2}{*}{\multicolumn{2}{|c|}{ Tipologi Kota }} & \multicolumn{4}{|c|}{ Daerah Tangkapan Air (Ha) } \\
\hline & & $<10$ & $10-100$ & $100-500$ & $>500$ \\
\hline & $\begin{array}{l}\text { Kota } \\
\text { Metropolitan }\end{array}$ & $2 \mathrm{Th}$ & $2-5 \mathrm{Th}$ & $5-10 \mathrm{Th}$ & $10-25 \mathrm{Th}$ \\
\hline - & Kota Besar & $2 \mathrm{Th}$ & $2-5 \mathrm{Th}$ & $2-5 \mathrm{Th}$ & $5-20 \mathrm{Th}$ \\
\hline- & Kota Sedang & $2 \mathrm{Th}$ & $2-5 \mathrm{Th}$ & $2-5 \mathrm{Th}$ & $5-10 \mathrm{Th}$ \\
\hline - & Kota Kecil & $2 \mathrm{Th}$ & $2 \mathrm{Th}$ & $2 \mathrm{Th}$ & $2-5 \mathrm{Th}$ \\
\hline
\end{tabular}

Sumber: Kementerian Pekerjaan Umum (2014)

\section{HEC-RAS}

HEC-RAS merupakan program aplikasi untuk memodelkan aliran di sungai, yang dibuat oleh Hydrologic Engineering Center (HEC) berupa model satu dimensi aliran permanen maupun tak permanen (steady and unsteady one-dimensional flow model) (Istiarto, 2014). HEC-RAS memiliki empat komponen model satu dimensi:

1. hitungan profil muka air aliran permanen,

2. simulasi aliran tak permanen,

3. hitungan transpor sedimen, dan

4. hitungan kualitas air.

Satu elemen penting dalam HEC-RAS adalah keempat komponen tersebut memakai data geometri yang sama, routine hitungan hidraulika yang sama, serta beberapa fitur desain hidraulik yang dapat diakses setelah hitungan profil muka air berhasil dilakukan.

\section{METODE PENELITIAN}

Penelitian ini menggunakan dua sumber data, yaitu data primer dan data sekunder. Data primer diperoleh dengan cara pengambilan gambar dan pengukuran langsung di lapangan dengan mengikuti protokol kesehatan new normal. Data sekunder diperoleh dari intansi terkait. Adapun data sekunder yang diperlukan yaitu:

1. Data curah hujan maksimum tiap bulan dalam 10 tahun terakhir dari Stasiun Hujan Kemayoran karena data dari Stasiun Hujan Kedoya Selatan tidak bisa didapat (BMKG Online, 2020)

2. Peta kontur Kelurahan Kedoya Utara (Suku Dinas Sumber Daya Air Jakarta Barat, 2020)

3. Peta arah aliran saluran yang terdapat di Kelurahan Kedoya Utara (Suku Dinas Sumber Daya Air Jakarta Barat. 2020)

4. Dimensi saluran PHB yang terdapat di Kelurahan Kedoya Utara (Suku Dinas Sumber Daya Air Jakarta Barat, 2020)

5. Peta jaringan drainase Kelurahan Kedoya Utara (Suku Dinas Sumber Daya Air Jakarta Barat, 2020)

Data curah hujan maksimum tiap bulan dalam 10 tahun terakhir dari Stasiun Hujan Kemayoran dikompilasi untuk mendapatkan data curah hujan harian maksimum dalam 1 tahun seperti yang tertera pada Tabel 2. 
Tabel 2. Data curah hujan yang dikompilasi dari data BMKG Online

\begin{tabular}{cc}
\hline Tahun & $\begin{array}{c}\text { Curah Hujan } \\
\text { Maksimum (mm) }\end{array}$ \\
\hline 2010 & 93 \\
2011 & 119,2 \\
2012 & 105,2 \\
2013 & 193,4 \\
2014 & 147,9 \\
2015 & 277,5 \\
2016 & 124,5 \\
2017 & 179,7 \\
2018 & 104,6 \\
2019 & 90,5 \\
\hline $\mathrm{Xr}$ & 143,6
\end{tabular}

Data kontur pada Gambar 4 digunakan untuk menentukan arah aliran saluran tersier untuk daerah yang tidak bisa ditinjau secara langsung ke lapangan.

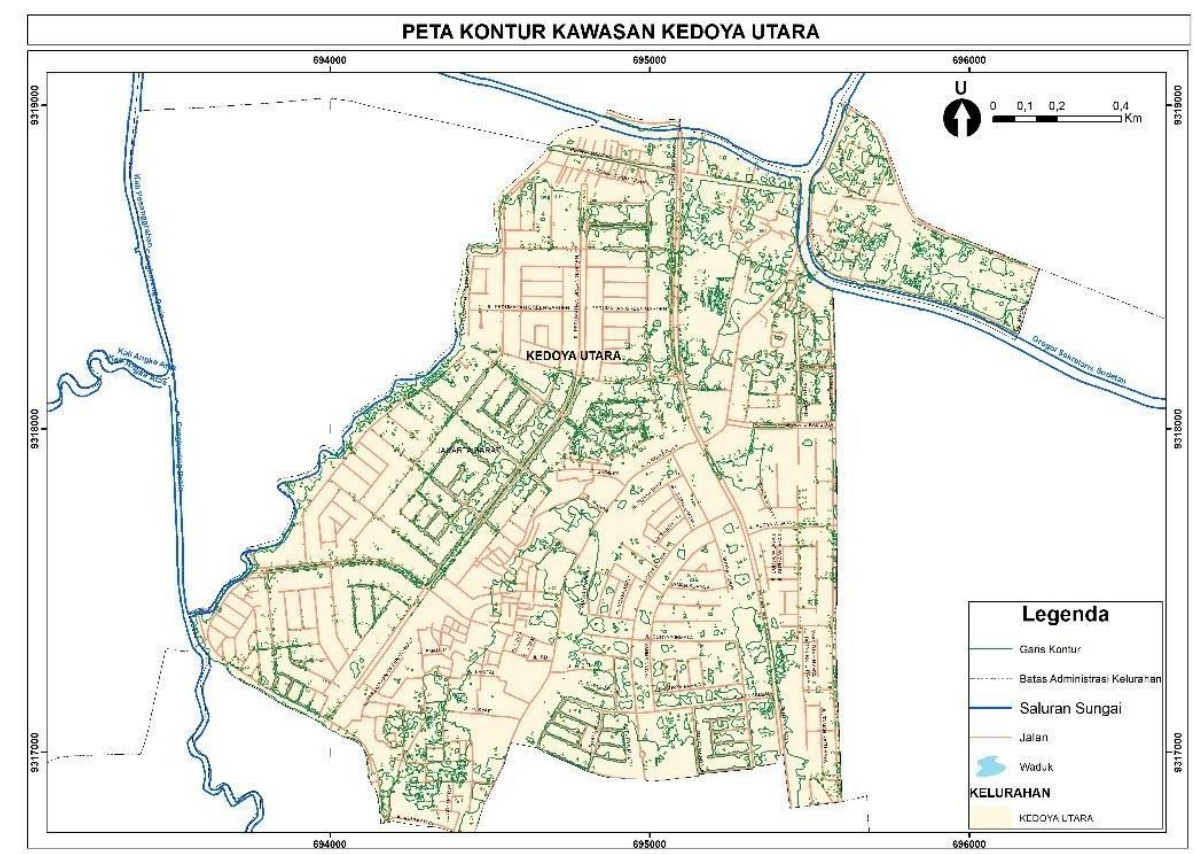

Gambar 4. Peta kontur kawasan Kedoya Utara (Sumber: Suku Dinas Sumber Daya Air Jakarta Barat, 2020)

Data arah aliran untuk saluran PHB pada Gambar 5 didapat dari Suku Dinas Sumber Daya Air Jakarta Barat, sedangkan data arah aliran untuk saluran tersier didapat melalui pengamatan langsung di lapangan. Data arah aliran ini digunakan untuk menentukan daerah tangkapan. 


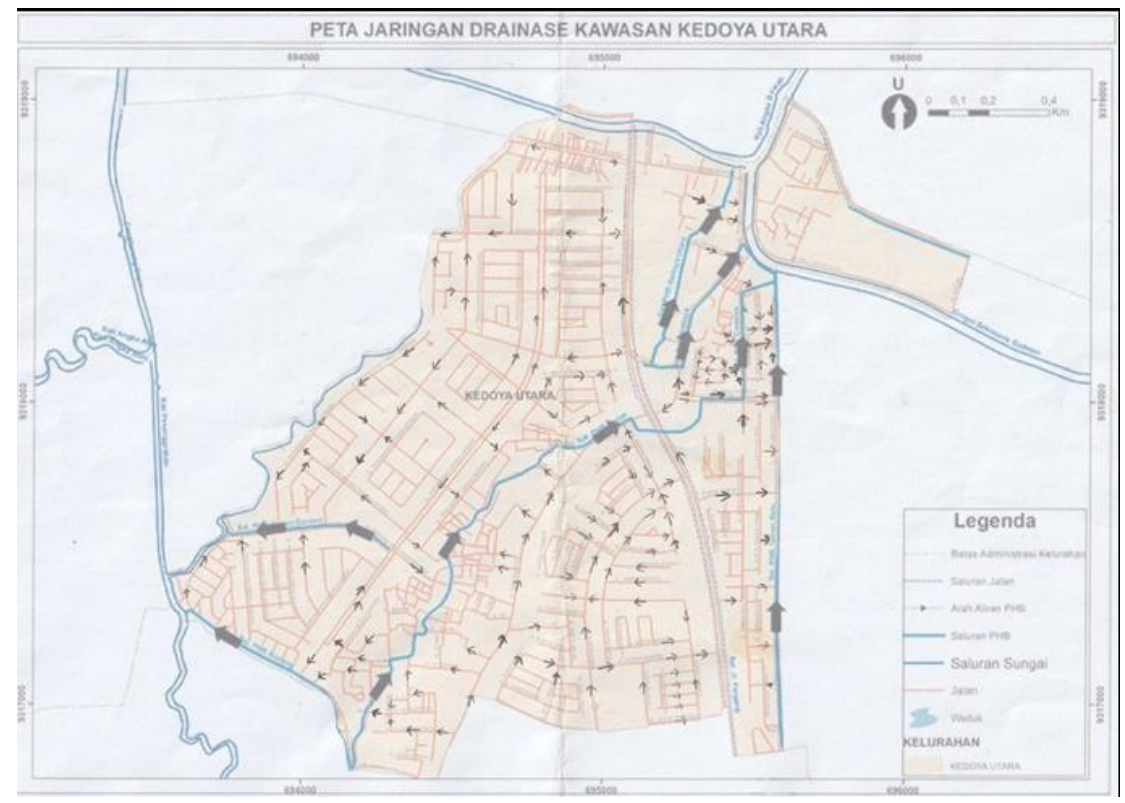

Gambar 5. Peta arah aliran jaringan drainase kawasan Kedoya Utara (Sumber: Suku Dinas Sumber Daya Air Jakarta Barat, 2020)

Data dimensi saluran yang digunakan dalam penelitian ini menggunakan data yang didapat dari Suku Dinas Sumber Daya Air Jakarta Barat dan pengukuran langsung di lapangan. Data yang didapat dari Suku Dinas Sumber Daya Air Jakarta Barat adalah data panjang saluran seperti yang tertera pada Gambar 6, sedangkan data yang didapat melalui pengukuran adalah data lebar dan tinggi saluran. Pengukuran lebar saluran dilakukan dengan menggunakan meteran, sedangkan pengukuran tinggi saluran dilakukan dengan menusukkan batang kayu/menjatuhkan tali yang diikatkan ke pemberat ke dasar saluran.

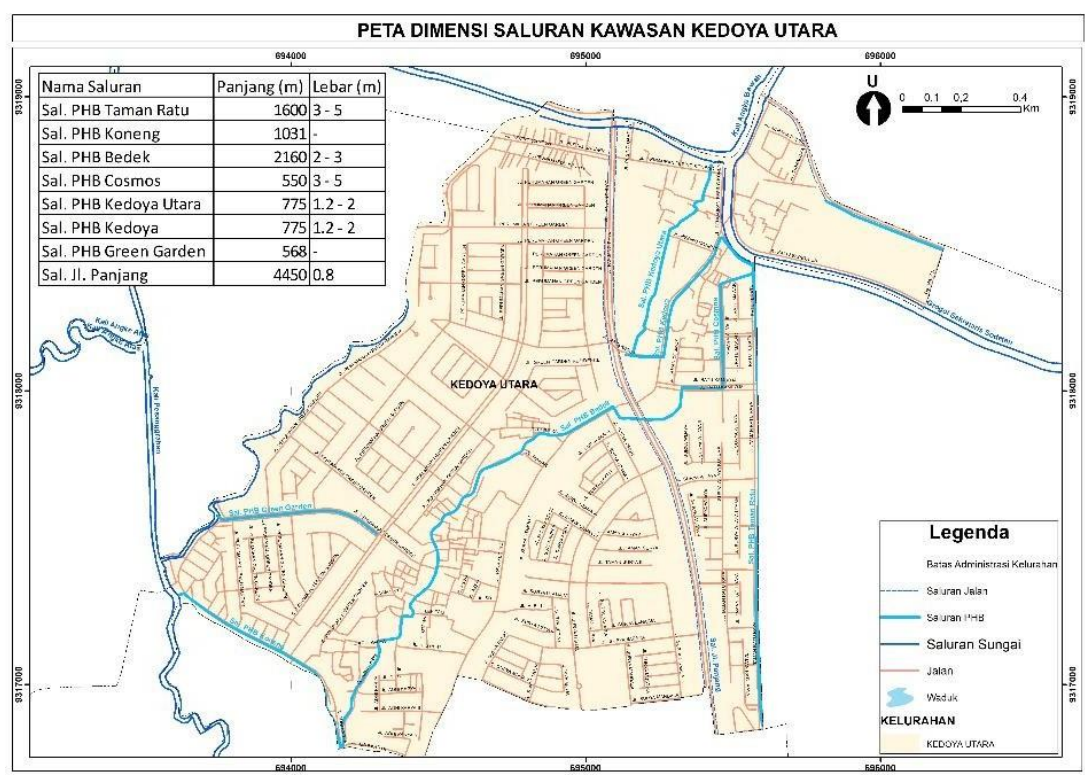

Gambar 6. Peta dimensi saluran kawasan Kedoya Utara (Sumber: Suku Dinas Sumber Daya Air Jakarta Barat, 2020)

Pengukuran dimensi saluran PHB dapat dilihat pada Gambar 7 dan pengamatan arah aliran saluran tersier dapat dilihat pada Gambar 8. Hal ini diperlukan untuk melengkapi data yang didapat dari Suku Dinas Sumber Daya Air Jakarta Barat. 


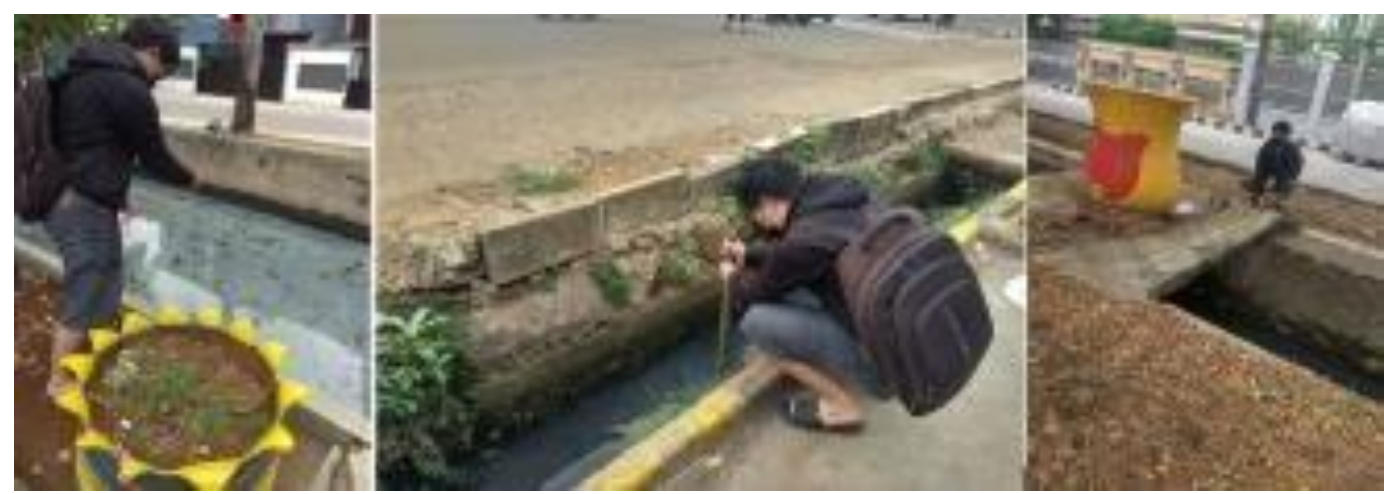

Gambar 7. Dokumentasi pengukuran dimensi saluran

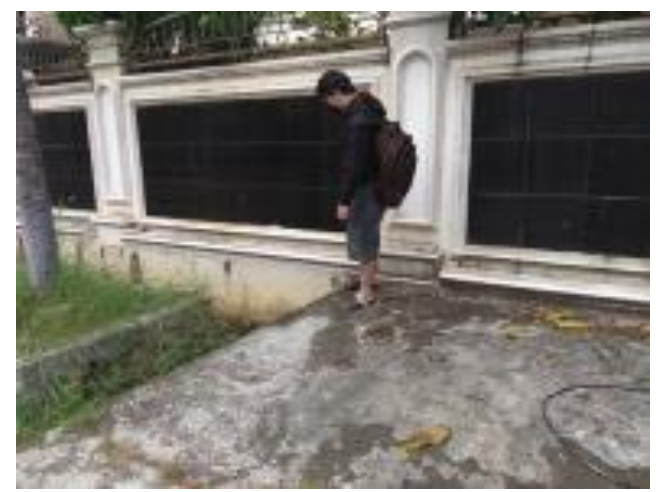

Gambar 8. Dokumentasi pengamatan arah aliran saluran tersier

Pengolahan data dilakukan dengan tahapan sebagai berikut:

1. Mengolah data curah hujan maksimum harian yang didapat dari Stasiun Hujan Kemayoran untuk mendapatkan curah hujan maksimum tahunan dalam 10 tahun terakhir

2. Mengolah curah hujan maksimal tahunan tersebut untuk mendapatkan curah hujan rencana

3. Mengolah data dimensi saluran untuk mendapatkan kapasitas saluran eksisting dan kecepatan aliran eksisting

4. Mengolah curah hujan rencana dan kecepatan aliran eksisting untuk mendapatkan intensitas hujan

5. Mengolah intensitas hujan untuk mendapatkan debit rencana

6. Mengolah debit rencana untuk mendapatkan dimensi saluran rencana yang mampu menampung debit rencana

\section{HASIL DAN PEMBAHASAN}

\section{Kesimpulan analisis uji Chi-Square dan Kolmogorov-Smirnov}

Subbab ini akan membahas kesimpulan yang didapat dari analisis uji Chi-Square dan Kolmogorov-Smirnov. Kesimpulan dari analisis uji Chi-Square dan uji Kolmogorov-Smirnov untuk data curah hujan yang didapat dapat dilihat pada Tabel 3 .

Tabel 3. Kesimpulan analisis uji Chi-Square dan Kolmogorov-Smirnov

\begin{tabular}{ccccccc}
\hline \multirow{2}{*}{ Metode } & \multicolumn{3}{c}{ Chi-Square } & \multicolumn{3}{c}{ Kolmogorov-Smirnov } \\
\cline { 2 - 6 } & X2 teoritis & X2 tabel & Keterangan & D max & D kritis & Keterangan \\
\hline Normal & 3 & 5,9915 & Ok & 0,1710 & 0,41 & Ok \\
Log Normal & 1 & 5,9915 & Ok & 0,1590 & 0,41 & Ok \\
Gumbel & 5 & 5,9915 & Ok & 0,1469 & 0,41 & Ok \\
Log Pearson Tipe III & 1 & 5,9915 & Ok & 0,1310 & 0,41 & Ok \\
\hline
\end{tabular}


Berdasarkan Tabel 3, maka dapat disimpulkan bahwa data curah hujan dapat dianalisis dengan menggunakan metode Log Pearson Tipe III karena memiliki nilai kritis yang lebih kecil dibanding metode lainnya.

\section{Analisis curah hujan rencana dengan metode distribusi Log Pearson Tipe III}

Subbab ini akan membahas analisis curah hujan rencana dengan metode Log Pearson Tipe III. Metode Log Pearson Tipe III dipilih setelah dilakukan tes dengan menggunakan metode Chi-Square dan Kolmogorov-Smirnov. Periode ulang 2 tahun dipilih karena luas daerah pengaliran dibawah 100 Ha (Kementerian Pekerjaan Umum Republik Indonesia, 2014). Berikut ini merupakan hasil analisis curah hujan rencana dengan metode Log Pearson Tipe III.

$$
\begin{aligned}
& \mathrm{T}=2 \text { tahun } \\
& \text { Cs } \quad=0,8802 \\
& \mathrm{~K}=-0,1448 \\
& \mathrm{X} \text { rata2 }=2,1292 \mathrm{~mm} \\
& \mathrm{~S} \quad=0,1577 \mathrm{~mm} \\
& \log \mathrm{Xt} \quad=2,1292+(-0,1448 \times 0,1577)=2,1064 \mathrm{~mm} / \mathrm{hari} \\
& \mathrm{Xt} \quad=127,7512 \mathrm{~mm} / \mathrm{hari}
\end{aligned}
$$

\begin{tabular}{|c|c|c|c|c|c|}
\hline \multirow{2}{*}{ No } & \multirow{2}{*}{ Nama Saluran } & \multicolumn{2}{|c|}{ Elevasi $(\mathrm{m})$} & \multirow{2}{*}{$\frac{\text { Panjang }}{(\mathrm{m})}$} & \multirow{2}{*}{$\begin{array}{c}\mathrm{S} \\
\left(10^{-3}\right)\end{array}$} \\
\hline & & Hulu & Hilir & & \\
\hline 1 & Sal. PHB Taman Ratu & 2 & 2 & 1600 & 1 \\
\hline 2 & Sal. PHB Koneng & 4 & 2 & 1031 & 1,9399 \\
\hline 3 & Sal. PHB Bedek & 4 & 2 & 2160 & 0,9259 \\
\hline 4 & Sal. PHB Cosmos & 2 & 2 & 550 & 1 \\
\hline 5 & Sal. PHB Kedoya Utara & 2 & 2 & 775 & 1 \\
\hline 6 & Sal. PHB Kedoya & 2 & 2 & 775 & 1 \\
\hline 7 & Sal. PHB Green Garden & 2 & 2 & 568 & 1 \\
\hline 8 & Sal. Jalan Panjang Kiri & 4 & 2 & 4450 & 0,4494 \\
\hline 9 & Sal. Jalan Panjang Kanan & 4 & 2 & 4450 & 0,4494 \\
\hline
\end{tabular}

\section{Analisis kapasitas saluran drainase eksisting}

\begin{tabular}{|c|c|c|c|c|c|c|c|c|}
\hline \multirow{2}{*}{ No } & \multirow{2}{*}{ Nama Saluran } & \multicolumn{3}{|c|}{ Dimensi (m) } & \multirow{2}{*}{$\begin{array}{c}\mathrm{s} \\
\left(10^{-3}\right)\end{array}$} & \multirow{2}{*}{$\mathrm{N}$} & \multirow{2}{*}{$\begin{array}{c}\mathrm{V} \\
(\mathrm{m} / \mathrm{s})\end{array}$} & \multirow{2}{*}{$\begin{array}{c}\mathrm{Q} \\
\left(\mathrm{m}^{3} / \mathrm{s}\right)\end{array}$} \\
\hline & & $\mathrm{b}$ & B & $\mathrm{h}$ & & & & \\
\hline 1 & Sal. PHB Taman Ratu & 5 & 5 & 2,2 & 1 & 0,0170 & 2,0657 & 22,7224 \\
\hline 2 & Sal. PHB Koneng & 5 & 4 & 1,5 & 1,9399 & 0,0220 & 1,9244 & 12,9898 \\
\hline 3 & Sal. PHB Bedek & 2,6 & 2,6 & 0,95 & 0,9259 & 0,0150 & 1,3599 & 3,3591 \\
\hline 4 & Sal. PHB Cosmos & 5 & 4,4 & 1,65 & 1 & 0,0220 & 1,4375 & 11,1479 \\
\hline 5 & Sal. PHB Kedoya Utara & 3 & 3 & 1,3 & 1 & 0,0150 & 1,6564 & 6,4599 \\
\hline 6 & Sal. PHB Kedoya & 3 & 3 & 1,3 & 1 & 0,0150 & 1,6564 & 6,4599 \\
\hline 7 & Sal. PHB Green Garden & 2,35 & 1,25 & 1,65 & 1 & 0,0220 & 1,0542 & 3,1310 \\
\hline 8 & Sal. Jalan Panjang Kiri & 0,8 & 0,8 & 1,25 & 0,4494 & 0,015 & 0,6376 & 0,6376 \\
\hline 9 & Sal. Jalan Panjang Kanan & 0,8 & 0,8 & 1,25 & 0,4494 & 0,015 & 0,6376 & 0,6376 \\
\hline
\end{tabular}

Subbab ini akan membahas analisis kapasitas saluran eksisting berdasarkan data dimensi saluran eksisting dengan menggunakan rumus Manning. Tahap pertama yang dilakukan adalah menghitung kemiringan dasar saluran seperti pada Tabel 4, kemudian dilanjutkan dengan perhitungan kapasitas saluran seperti pada Tabel 5.

Tabel 4. Hasil perhitungan kemiringan dasar saluran

Tabel 5. Hasil perhitungan kapasitas saluran drainase eksisting 


\section{Analisis intensitas hujan dengan metode Mononobe}

Subbab ini akan membahas analisis intensitas hujan dengan menggunakan metode Mononobe. Pada Tabel 6 dapat dilihat hasil perhitungan intensitas hujan dengan metode Mononobe.

Tabel 6. Hasil perhitungan intensitas hujan dengan metode Mononobe

\begin{tabular}{|c|c|c|c|c|c|}
\hline \multirow{3}{*}{ No } & \multirow{3}{*}{ Saluran } & \multirow{3}{*}{$\begin{array}{c}\mathrm{L} \\
\text { saluran } \\
(\mathrm{m})\end{array}$} & \multirow{3}{*}{$\underset{(\mathrm{m} / \mathrm{s})}{\mathrm{V}}$} & \multirow{3}{*}{$\begin{array}{c}\mathrm{Tc} \\
(\mathrm{jam})\end{array}$} & \multirow{2}{*}{$\begin{array}{c}\text { Curah Hujan Rencana }(\mathrm{mm}) \\
127,7512 \\
\end{array}$} \\
\hline & & & & & \\
\hline & & & & & Intensitas Hujan (mm/jam) \\
\hline 1 & Sal. PHB Taman Ratu & 1600 & 2,0657 & 0,3652 & 86,6911 \\
\hline 2 & Sal. PHB Koneng & 1031 & 1,9244 & 0,3405 & 90,8299 \\
\hline 3 & Sal. PHB Bedek & 2160 & 1,3599 & 0,6245 & 60,6168 \\
\hline 4 & Sal. PHB Cosmos & 550 & 1,4375 & 0,7308 & 54,5874 \\
\hline 5 & Sal. PHB Kedoya Utara & 775 & 1,6564 & 0,2383 & 115,2239 \\
\hline 6 & Sal. PHB Kedoya & 775 & 1,6564 & 0,2466 & 112,6136 \\
\hline 7 & Sal. PHB Green Garden & 568 & 1,0542 & 0,3497 & 89,2336 \\
\hline 8 & Sal. Jalan Panjang Kiri & 4450 & 0,6376 & 2,1553 & 26,5436 \\
\hline 9 & Sal. Jalan Panjang Kanan & 4450 & 0,6376 & 2,0803 & 27,1778 \\
\hline
\end{tabular}

\section{Analisis debit rencana}

Subbab ini akan membahas analisis debit rencana berdasarkan data curah hujan yang didapat menggunakan metode rasional. Metode rasional digunakan karena luas daerah aliran tidak lebih dari 5000 ha (SNI 2415:2016, 2016). Besarnya nilai luas tangkapan diperoleh melalui pengukuran daerah tangkapan menggunakan aplikasi Google Maps seperti yang terlihat pada Gambar 9. Hasil perhitungan debit rencana dapat dilihat pada Tabel 7.

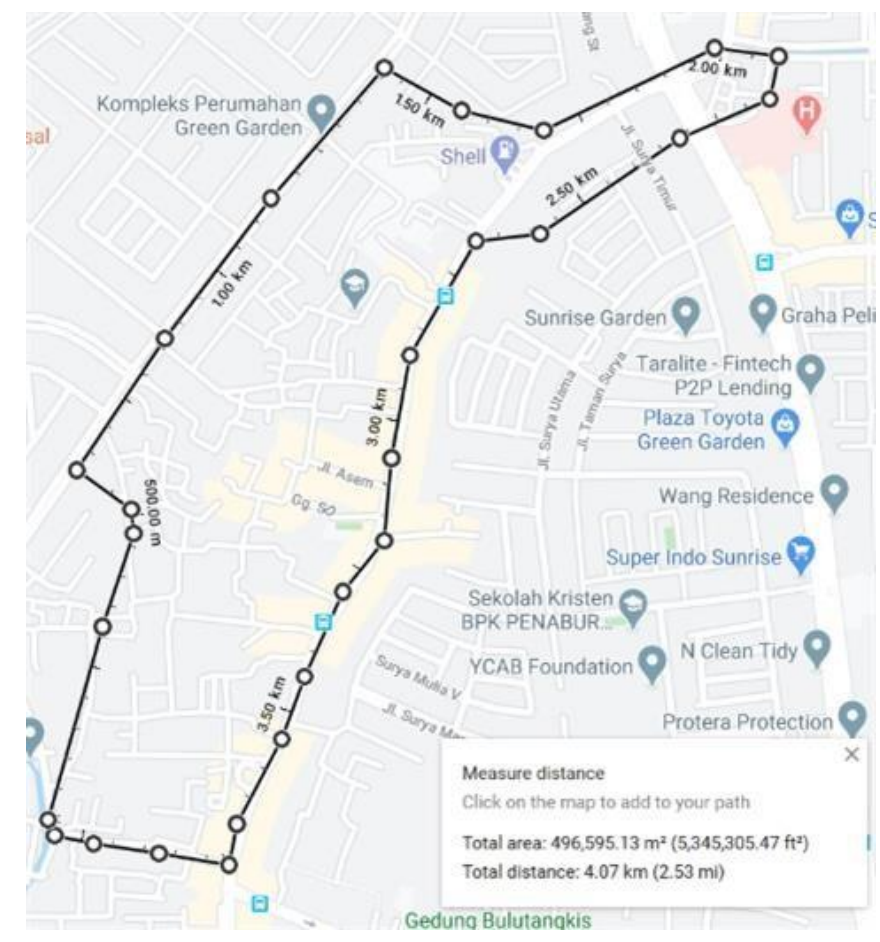

Gambar 9. Pengukuran luas tangkapan Saluran PHB Bedek dengan aplikasi Google Maps 
Tabel 7. Hasil perhitungan debit rencana

\begin{tabular}{clccc}
\hline No & \multicolumn{1}{c}{ Saluran } & $\begin{array}{c}\text { Luas Tangkapan } \\
\text { (ha) }\end{array}$ & C & $\begin{array}{c}\text { Debit } \\
\text { Rencana } \\
\left(\mathrm{m}^{3} / \mathrm{s}\right)\end{array}$ \\
\hline 1 & Sal. PHB Taman Ratu & 24,3755 & 0,65 & 3,8184 \\
2 & Sal. PHB Koneng & 7,3508 & 0,65 & 1,2065 \\
3 & Sal. PHB Bedek & 49,6595 & 0,65 & 5,4394 \\
4 & Sal. PHB Cosmos & 58,1852 & 0,65 & 5,7394 \\
5 & Sal. PHB Kedoya Utara & 4,6706 & 0,65 & 0,9725 \\
6 & Sal. PHB Kedoya & 8,2704 & 0,65 & 1,6830 \\
7 & Sal. PHB Green Garden & 54,8722 & 0,65 & 8,8479 \\
8 & Sal. Jalan Panjang Kiri & 70,3909 & 0,65 & 3,3762 \\
9 & Sal. Jalan Panjang Kanan & 14,6068 & 0,65 & 0,7173 \\
\hline
\end{tabular}

\section{Analisis perbandingan debit rencana dan kapasitas saluran eksisting}

Subbab ini akan membahas analisis perbandingan antara debit rencana dan kapasitas saluran eksisting. Hasil perbandingan antara kapasitas saluran eksisting dan debit rencana dapat dilihat pada Tabel 8.

Tabel 8. Perbandingan debit rencana dan kapasitas saluran eksisting

\begin{tabular}{llccc}
\hline No & \multicolumn{1}{c}{ Saluran } & $\begin{array}{c}\text { Kapasitas } \\
\text { Saluran } \\
\text { Eksisting } \\
\left(\mathrm{m}^{3} / \mathrm{s}\right)\end{array}$ & $\begin{array}{c}\text { Debit Rencana } \\
\left(\mathrm{m}^{3} / \mathrm{s}\right)\end{array}$ & Keterangan \\
& & & \\
\hline 1 & Sal. PHB Taman Ratu & 22,7224 & 3,8184 & OK \\
2 & Sal. PHB Koneng & 12,9898 & 1,2065 & OK \\
3 & Sal. PHB Bedek & 3,3591 & 5,4394 & - \\
4 & Sal. PHB Cosmos & 11,1479 & 5,7394 & OK \\
5 & Sal. PHB Kedoya Utara & 6,4599 & 0,9725 & OK \\
6 & Sal. PHB Kedoya & 6,4599 & 1,6830 & OK \\
7 & Sal. PHB Green Garden & 3,1310 & 8,8479 & - \\
8 & Sal. Jalan Panjang Kiri & 0,6376 & 3,3762 & - \\
9 & Sal. Jalan Panjang Kanan & 0,6376 & 0,7173 & - \\
\hline
\end{tabular}

Berdasarkan Tabel 8 dapat dilihat bahwa Saluran PHB Taman Ratu, Saluran PHB Koneng, Saluran PHB Cosmos, Saluran PHB Kedoya Utara, dan Saluran PHB Kedoya masih dapat menampung debit dari hujan rencana. Sementara itu Saluran PHB Bedek, Saluran PHB Green Garden, Saluran Jalan Panjang Kiri, dan Saluran Jalan Panjang Kanan tidak dapat menampung debit dari hujan rencana. Hal ini sesuai dengan kenyataan di lapangan dimana lokasi-lokasi tersebut tergenang banjir pada tahun 2016 dengan curah hujan pada saat itu sebesar $124,5 \mathrm{~m}^{3} / \mathrm{s}$ yang sedikit lebih rendah dibanding curah hujan rencana sebesar $127,7512 \mathrm{~m}^{3} / \mathrm{s}$ dengan titik genangan terdalam berada di Jalan Panjang.

\section{Perencanaan dimensi saluran}

Subbab ini akan membahas perencanaan dimensi saluran agar saluran mampu menampung debit rencana. Dalam perencanaan ini, bentuk Saluran PHB Green Garden diubah menjadi bentuk persegi agar saluran mampu menampung debit yang lebih besar tanpa perlu menambah lebar saluran terlalu banyak. Perhitungan ukuran dimensi saluran dilakukan dengan metode trial \& error. Hasil perhitungan perencanaan dimensi saluran dan kapasitas dari saluran rencana dapat dilihat pada Tabel 9. 
Tabel 9. Hasil perhitungan perencanaan dimensi saluran

\begin{tabular}{llccccccc}
\hline No & \multicolumn{1}{c}{ Saluran } & $\mathrm{N}$ & $\begin{array}{c}\mathrm{s} \\
\left(10^{-3}\right)\end{array}$ & $\begin{array}{c}\text { Tinggi } \\
\text { Jagaan } \\
(\mathrm{m})\end{array}$ & $\begin{array}{c}\mathrm{h} \\
(\mathrm{m})\end{array}$ & $\begin{array}{c}\mathrm{B} \\
(\mathrm{m})\end{array}$ & $\begin{array}{c}\text { V } \\
(\mathrm{m} / \mathrm{s})\end{array}$ & $\begin{array}{c}\text { Kapasitas rencana } \\
\left(\mathrm{m}^{3} / \mathrm{s}\right)\end{array}$ \\
\hline 1 & Sal. PHB Bedek & 0,015 & 0,9259 & 0,3 & 1,60 & 2,85 & 1,5684 & 5,8109 \\
2 & Sal. PHB Green Garden & 0,015 & 1 & 0,4 & 1,90 & 3,70 & 1,8595 & 10,3200 \\
3 & Sal. Jalan Panjang Kiri & 0,015 & 0,4494 & 0,25 & 1,60 & 3,10 & 1,1370 & 4,7583 \\
4 & Sal. Jalan Panjang Kanan & 0,015 & 0,4494 & 0,2 & 1,60 & 0,80 & 0,6489 & 0,7268 \\
\hline
\end{tabular}

\section{Analisis intensitas hujan dengan dimensi rencana}

Subbab ini akan membahas analisis intensitas hujan berdasarkan dimensi rencana. Intensitas hujan perlu dihitung lagi dengan menggunakan data dimensi rencana untuk menyesuaikan nilai intensitas hujan dengan dimensi rencana. Hal ini desebabkan oleh berubahnya nilai $\mathrm{V}$ dan tc akibat berubahnya ukuran dimensi saluran. Hasil perhitungan intensitas hujan dengan dimensi rencana dapat dilihat pada Tabel 10.

Tabel 10. Hasil perhitungan analisis intensitas hujan dengan dimensi rencana

\begin{tabular}{|c|c|c|c|c|c|}
\hline \multirow{3}{*}{ No } & \multirow{3}{*}{ Saluran } & \multirow{3}{*}{$\begin{array}{c}\mathrm{L} \\
\text { saluran } \\
(\mathrm{m})\end{array}$} & \multirow{3}{*}{$\begin{array}{c}\mathrm{V} \\
(\mathrm{m} / \mathrm{s})\end{array}$} & \multirow{3}{*}{$\begin{array}{c}\mathrm{Tc} \\
(\mathrm{jam})\end{array}$} & \multirow{2}{*}{$\begin{array}{c}\text { Curah Hujan Rencana (mm) } \\
127,7512\end{array}$} \\
\hline & & & & & \\
\hline & & & & & Intensitas Hujan (mm/jam) \\
\hline 1 & Sal. PHB Bedek & 2160 & 1,5684 & 0,5659 & 64,7353 \\
\hline 2 & Sal. PHB Green Garden & 568 & 1,8595 & 0,2849 & 102,3016 \\
\hline 3 & Sal. Jalan Panjang Kiri & 4450 & 1,1370 & 1,3038 & 37,1088 \\
\hline 4 & Sal. Jalan Panjang Kanan & 4450 & 0,6489 & 2,0466 & 27,4755 \\
\hline
\end{tabular}

\section{Analisis debit rencana dengan dimensi rencana}

Subbab ini akan membahas analisis debit rencana berdasarkan dimensi rencana. Debit rencana perlu dihitung lagi dengan menggunakan data dimensi rencana untuk menyesuaikan nilai debit rencana dengan dimensi rencana. Hal ini disebabkan oleh berubahnya nilai intensitas hujan akibat berubahnya ukuran dimensi saluran. Hasil perhitungan debit rencana dengan dimensi rencana dapat dilihat pada Tabel 11.

Tabel 11. Hasil perhitungan analisis debit rencana dengan dimensi rencana

\begin{tabular}{clccc}
\hline No & \multicolumn{1}{c}{ Saluran } & $\begin{array}{c}\text { Luas Tangkapan } \\
\text { (ha) }\end{array}$ & C & $\begin{array}{c}\text { Debit Rencana } \\
\left(\mathrm{m}^{3} / \mathrm{s}\right)\end{array}$ \\
\hline 1 & Sal. PHB Bedek & 49,6595 & 0,65 & 5,8090 \\
2 & Sal. PHB Green Garden & 54,8722 & 0,65 & 10,1436 \\
3 & Sal. Jalan Panjang Kiri & 70,3909 & 0,65 & 4,7201 \\
4 & Sal. Jalan Panjang Kanan & 14,6068 & 0,65 & 0,7252 \\
\hline
\end{tabular}

\section{Analisis perbandingan debit rencana dengan kapasitas saluran rencana}

Subbab ini akan membahas perbandingan antara debit rencana dengan kapasitas saluran rencana. Hasil perbandingan antara kapasitas saluran rencana dan debit rencana dapat dilihat pada Tabel 12. 
Tabel 12. Perbandingan kapasitas saluran rencana dan debit rencana

\begin{tabular}{llccc}
\hline No & \multicolumn{1}{c}{ Saluran } & $\begin{array}{c}\text { Kapasitas } \\
\text { Saluran } \\
\text { Rencana } \\
(\mathrm{m} 3 / \mathrm{s})\end{array}$ & $\begin{array}{c}\text { Debit } \\
\text { Rencana } \\
(\mathrm{m} 3 / \mathrm{s})\end{array}$ & Keterangan \\
\hline 1 & Sal. PHB Bedek & 5,8109 & 5,8090 & OK \\
2 & Sal. PHB Green Garden & 10,3200 & 10,1436 & OK \\
3 & Sal. Jalan Panjang Kiri & 4,7583 & 4,7201 & OK \\
4 & Sal. Jalan Panjang Kanan & 0,7268 & 0,7252 & OK \\
\hline
\end{tabular}

Berdasarkan Tabel 12 dapat dilihat bahwa kapasitas keempat saluran tersebut sudah dapat menampung debit rencana.

\section{Perbandingan dimensi eksisting dan dimensi rencana}

Subbab ini akan membahas perbandingan antara dimensi saluran eksisting dan dimensi saluran rencana. Perbandingan dimensi awal saluran dan dimensi rencana saluran dapat dilihat pada Tabel 13.

Tabel 13. Perbandingan dimensi saluran eksisting dan dimensi saluran rencana

\begin{tabular}{llcccccc}
\hline \multirow{2}{*}{ No } & \multirow{2}{*}{ Saluran } & \multicolumn{3}{c}{ Dimensi Eksisting $(\mathrm{m})$} & \multicolumn{3}{c}{ Dimensi Rencana $(\mathrm{m})$} \\
\cline { 3 - 8 } & & $\mathrm{b}$ & $\mathrm{B}$ & $\mathrm{h}$ & $\mathrm{b}$ & $\mathrm{B}$ & $\mathrm{h}$ \\
\hline 1 & Sal. PHB Bedek & 2,60 & 2,60 & 0,95 & 2,85 & 2,85 & 1,60 \\
2 & Sal. PHB Green Garden & 2,35 & 1,25 & 1,65 & 3,70 & 3,70 & 1,90 \\
3 & Sal. Jalan Panjang Kiri & 0,80 & 0,80 & 1,25 & 3,10 & 3,10 & 1,60 \\
4 & Sal. Jalan Panjang Kanan & 0,80 & 0,80 & 1,25 & 0,80 & 0,80 & 1,60 \\
\hline
\end{tabular}

\section{Permodelan tinggi muka air saluran bedek eksisting}

Subbab ini akan membahas permodelan tinggi muka air saluran eksisting berdasarkan debit rencana dengan menggunakan aplikasi HEC-RAS.

Saluran PHB Bedek memiliki dinding saluran yang terbuat dari beton. Pada saluran ini terdapat sampah yang dapat menghambat laju air dalam saluran. Debit yang harus ditampung oleh saluran ini sebesar 5,4394 m3/s, sementara saluran hanya mampu menampung debit sebesar 3,3591 m3/s. Hal ini menyebabkan saluran tidak mampu menampung debit rencana. Hasil permodelan Saluran PHB Bedek eksisting dapat dilihat pada Gambar 10.
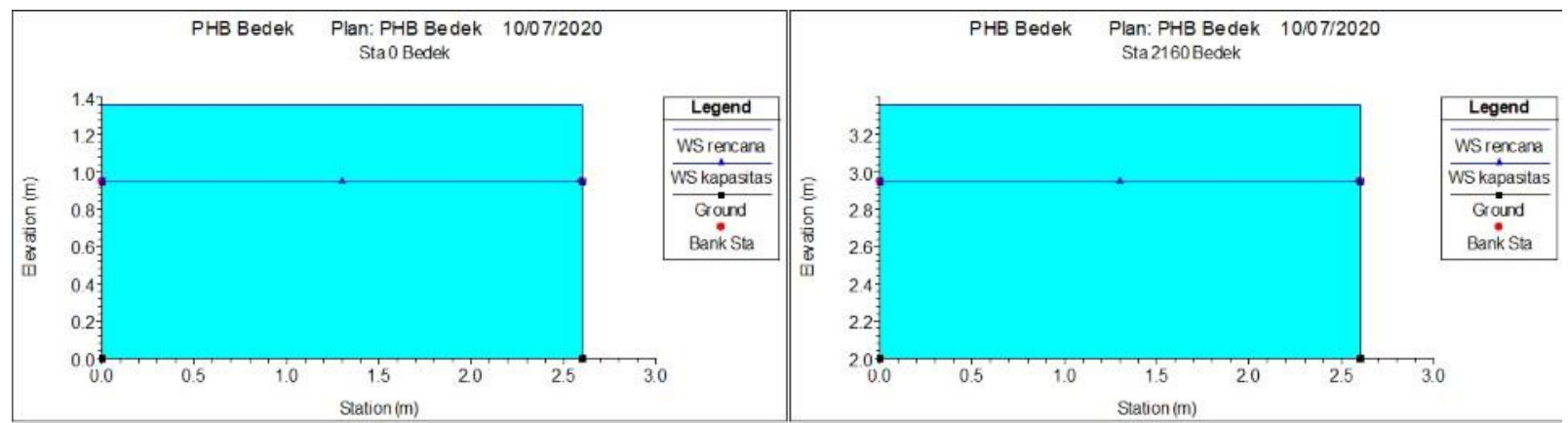

Gambar 10. Hasil Permodelan Tinggi Muka Air Saluran PHB Bedek Bagian Hilir (kiri) dan hulu (kanan)

Pada Gambar 10 dapat dilihat bahwa ketinggian air akibat debit rencana (WS rencana) melebihi ketinggi air yang mampu ditampung saluran (WS kapasitas). 


\section{Permodelan tinggi muka air saluran bedek rencana}

Subbab ini akan membahas permodelan tinggi muka air untuk saluran dengan dimensi rencana yang telah di desain agar mampu menampung debit rencana.

Dimensi eksisting pada Saluran PHB Bedek tidak mampu menampung debit rencana sehingga perlu dilakukan redesign untuk mendapatkan dimensi yang mampu menampung debit rencana. Setelah redesign dilakukan maka Saluran PHB Bedek mampu menampung debit sebesar $5,8109 \mathrm{~m}^{3} / \mathrm{s}$, sehingga mampu menampung debit rencana sebesar $5,809 \mathrm{~m}^{3} / \mathrm{s}$. Hal ini sesuai dengan hasil permodelan yang dapat dilihat pada Gambar 11 .

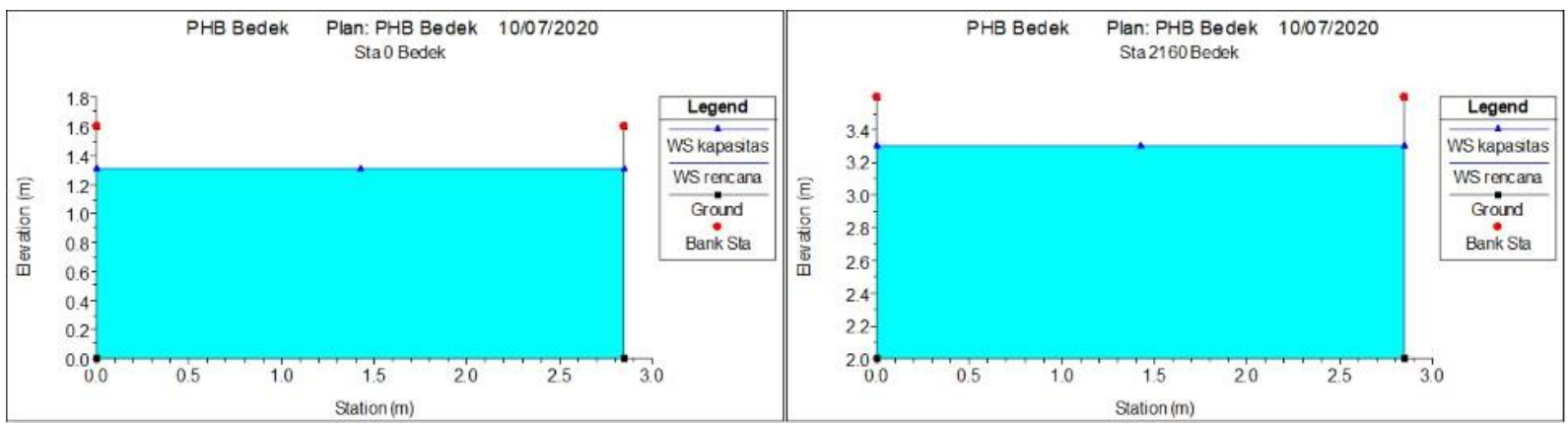

Gambar 11. Hasil Permodelan Tinggi Muka Air Saluran PHB Bedek Dengan Dimensi Rencana Bagian Hilir (kiri) dan hulu (kanan)

Pada Gambar 11 dapat dilihat bahwa Saluran PHB Bedek sudah mampu menampung debit rencana karena ketinggian air akibat debit rencana (WS rencana) lebih kecil daripada ketinggian air yang mampu ditampung saluran (WS kapasitas).

\section{KESIMPULAN DAN SARAN}

\section{Kesimpulan}

Berasarkan hasil analisis maka dapat disimpulkan:

1. Genangan air di Kelurahan Kedoya Utara disebabkan oleh kurangnya kapasitas saluran drainase eksisting dari Saluran PHB Bedek, Saluran PHB Green Garden, Saluran Jalan Panjang Kiri, dan Saluran Jalan Panjang Kanan

2. Terdapat 4 saluran drainase eksisting yang tidak mampu menampung debit rencana maksimum, yaitu Saluran PHB Bedek, Saluran PHB Green Garden, Saluran Jalan Panjang Kiri, dan Saluran Jalan Panjang Kanan

\section{Saran}

Berdasarkan hasil analisis maka ada beberapa saran, yaitu:

1. Disarankan untuk memperbesar dimensi Saluran PHB Bedek, Saluran PHB Green Garden, Saluran Jalan Panjang Kiri, dan Saluran Jalan Panjang Kanan agar saluran mampu menampung debit rencana

2. Untuk penelitian yang akan datang disarankan untuk memperhitungkan debit limpasan dari saluran tersier

3. Untuk penelitian yang akan datang lebih baik jika pengambilan data dimensi saluran dapat dilakukan dengan menggunakan teodolit dan menggunakan data debit eksisting yang didapat dari masterplan/dokumen desain yang tersedia.

\section{DAFTAR PUSTAKA}

Badan Standardisasi Nasional. "SNI 2415:2016 tata cara perhitungan debit banjir rencana." Badan Penelitian dan Pengembangan PUPR (2016).

BMKG Online. "Data iklim." Data Online Pusat Database - BMKG (2020).

DetikNews. "Kedoya Utara jadi langganan banjir setiap tahun, ini penyebabnya." DetikNews (2016).

Istiarto. "Simulasi aliran 1-dimensi dengan bantuan paket program hidrodinamika HEC-RAS." Departemen Teknik Sipil dan Lingkungan Fakultas Teknik UGM (2014). 
Kementerian Pekerjaan Umum. "Tentang penyelenggaraan drainase perkotaan." Peraturan Menteri Pekerjaan Umum Nomor 12/PRT/M/2014 (2014).

Pemerintah Provinsi DKI Jakarta. "Data jumlah penduduk provinsi DKI Jakarta berdasarkan kelompok usia dan jenis kelamin." Badan Pusat Statistik Provinsi DKI Jakarta (2018).

Suku Dinas Sumber Daya Air Jakarta Barat. "Data drainase kawasan Kedoya Utara." Jakarta: Suku Dinas Sumber Daya Air Jakarta Barat, 30 Januari 2020. 
